\title{
Donor-site morbidity of the inferior gluteal artery perforator flap for breast reconstruction in teenagers
}

\author{
Emilie Godbout MD, Lucie Farmer PHT, Patricia Bortoluzzi MD FRCSC, Louise Caouette Laberge MD FRCSC
}

E Godbout, L Farmer, P Bortoluzzi, L Caouette Laberge. Donor-site morbidity of the inferior gluteal artery perforator flap for breast reconstruction in teenagers. Can J Plast Surg 2013;21(1):19-22.

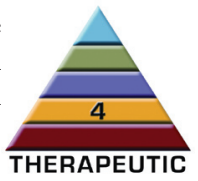

BACKGROUND/OBJECTIVE: Few options, apart from the buttock area, are available for autologous breast reconstruction in thin teenagers. The aim of the present study was to objectively evaluate and compare donor-site morbidity of the inferior gluteal artery perforator (IGAP) flap with that of the previously described inferior gluteal musculocutaneous flap.

METHOD: A retrospective review of all IGAP flaps for breast reconstruction performed in teenagers between June 2006 and April 2011 at the Centre Hospitalier Universitaire Sainte-Justine, Montreal, Quebec, was performed. Patients were invited to undergo a specific physical evaluation and complete a questionnaire on aesthetic and functional outcomes.

RESULTS: Thirteen records and 11 photographic charts were reviewed. Lateral buttock flattening was noticeable in nine of 11 cases. Three patients experienced some degree of inferior displacement of the gluteal crease. All six patients available for the appointment presented with a zone of dysesthesia or hypoesthesia in the territory of the operated buttock and/or posterior thigh. No motor impairment was found. The questionnaire, completed by eight patients, revealed that six were satisfied or very satisfied with the surgery. Appearance of the operated buttock was rated 3.4 on a scale from 1 to 5 ( 5 = normal) compared with the normal side.

CONCLUSIONS: The IGAP flap remains a suitable option for breast reconstruction in slim teenagers. Similar to the myocutaneous flap, the major donor-site morbidity of the IGAP flap remains sensory impairment involving the posterior femoral cutaneous nerve. There is, however, less visible lateral depression when it is harvested as a perforator flap.

Key Words: Donor-site morbidity; IGAP; Inferior gluteal artery perforator flap; Teenage breast reconstruction

\author{
La morbidité au foyer de prélèvement du lambeau de \\ l'artère perforante du grand fessier inférieur en cas de \\ reconstruction mammaire chez des adolescentes
}

HISTORIQUE ET OBJECTIF : Il existe peu de foyers de prélèvement, à part la région des fesses, pour effectuer une reconstruction mammaire autologue chez des adolescentes minces. La présente étude visait à évaluer et à comparer objectivement la morbidité au foyer de prélèvement du lambeau de l'artère perforante du grand fessier inférieur (APFI) à celle décrite antérieurement au foyer de prélèvement du lambeau musculocutané du grand fessier inférieur.

MÉTHODOLOGIE : Les chercheurs ont effectué une analyse rétrospective de tous les lambeaux de l'APFI en vue d'une reconstruction mammaire chez des adolescentes entre juin 2006 et avril 2011 au Centre hospitalier universitaire Sainte-Justine de Montréal, au Québec. Les patientes étaient invitées à subir une évaluation physique précise et à remplir un questionnaire sur les issues esthétiques et fonctionnelles.

RÉSULTATS : Les chercheurs ont analysé 13 dossiers médicaux et 11 dossiers photographiques. Ils ont remarqué un aplatissement de la partie latérale de la fesse dans neuf des 11 cas. Trois patientes ont subi un certain degré de déplacement inférieur du pli fessier. Les six patientes disponibles pour le rendezvous présentaient une zone de dysesthésie ou d'hypoesthésie dans le territoire de la fesse opérée ou de la cuisse postérieure. Aucune n'avait d'atteinte motrice. Le questionnaire, qu'avaient rempli huit patientes, a révélé que six d'entre elles étaient satisfaites ou très satisfaites de l'opération. L'apparence de la fesse opérée a obtenu une note de 3,4 sur une échelle de 1 à 5 ( 5 =normal) par rapport au côté normal.

CONCLUSIONS : Le lambeau de l'APFI demeure une possibilité acceptable pour procéder à une reconstruction mammaire chez des adolescentes minces. À l'instar du lambeau myocutané, la principale morbidité au foyer de prélèvement du lambeau de l'APFI est une atteinte sensorielle touchant le nerf cutané fémoral postérieur. La dépression latérale est toutefois moins visible lorsqu'on fait le prélèvement sous forme de lambeau de l'artère perforante.

\section{METHODS}

The present study was approved by the Scientific and Ethics Committee of the Centre Hospitalier Universitaire Sainte-Justine, Montreal, Quebec. The methodology used in the present study was the same as that described in the authors' previous report on the donor-site morbidity of the inferior gluteal musculocutaneous flap (1).

All cases of breast reconstruction using an IGAP flap in teenagers performed between 2006 and 2011 were included. The patients' charts were reviewed for demographic data, comorbidities, smoking and flap weight, as well as perioperative and postoperative courses. Photographic assessment (with consent) during the patients' follow-up visits was used for aesthetic evaluation of the buttock shape and projection, thigh deformity and scar quality.

The second part of the present study consisted of a physical evaluation and a questionnaire. The aesthetic aspect of the donor site addressed the scar and the buttock contour. The scar was examined for pigmentation, texture and dimension. The buttock was evaluated for possible flattening, lateral thigh depression and position of the gluteal crease. Sensory assessment was performed first by running a finger along the posterior thigh to delineate a possible zone of dysesthesia (defined as an unpleasant, abnormal sensation). Subsequently, the smallest Semmes-Weinstein monofilament felt on the skin of the normal buttock and thigh was used to better define the borders of that perforator variant of tissue harvesting, the IGAP flap.

Division of Plastic Surgery, Centre Hospitalier Universitaire Sainte-Justine, Montréal, Quebec

Correspondence: Dr Louise Caouette Laberge, Centre Hospitalier Universitaire Sainte-Justine, 3175 Côte-Sainte-Catherine, Room 7907,

Montreal, Quebec H3T 1C5. Telephone 514-345-4771, fax 514-345-4964, e-mail l.caouette-laberge@umontreal.ca 


\section{TABLE 1}

Demographic data at the time of surgery

Patients, $n$ 13

Age, years

$18.1(16.7-19.9)$

Weight, kg

$65.1(49.2-96.6)$

Smoking at the time of surgery, $\mathrm{n}$

0 (3 unknown)

Harvested flap weight, $g$

$324(175-519)$

Follow-up, months

$24.0(1.5-66.5)$

Data presented as mean (range) unless otherwise indicated

zone on the operated side. The same monofilament was tested over the scar and inside the delineated zone. If it was not sensed (which signified a zone of hypoesthesia), the next bigger monofilament was used until the patient indicated sensation. Photographs of the donor site in the standing position were taken from posterior, superior and lateral views. Photographs of the zone of dysesthesia or hypoesthesia were also taken.

Functional assessment was performed by a physiotherapist and included evaluation of posture, pelvic stability using the Trendelenburg test and sciatic nerve testing using the Lasègue test. Gluteus maximus muscle strength was measured by hip extension with flexed knee and by hip abduction. It was rated on a scale of 0 to 5 (13) and the two sides were compared. The functional capacity was evaluated using the standardized 6 min walk test (14), in which patients are asked to "walk as far they can during six minutes". The total distance walked ranges from $400 \mathrm{~m}$ to $700 \mathrm{~m}$ in healthy subjects.

Finally, a self-administered adapted quality-of-life questionnaire with a visual scale from 1 to 5 was given to the patients. Outcomes assessed were the patient's degree of satisfaction with the surgery, appearance of the donor site, functional impact of the surgery in daily activities and sports, and the presence or absence of symptoms such as pain, numbness and hypoesthesia over the posterior thigh. The patients were encouraged to add any other symptoms or concerns at the end of the questionnaire.

\section{RESULTS}

Thirteen patients underwent breast reconstruction using the IGAP flap between 2006 and 2011 at the Centre Hospitalier Universitaire Sainte-Justine. The patients' files were reviewed and 11 had photographic documentation in the database that were evaluated. Six patients agreed to participate in the second part of the study and two additional patients who could not attend the appointment participated in a telephone interview. Patient demographic data are summarized in Table 1. One patient had Crohn disease and was taking 6-mercaptopurine. Ten patients reported not smoking at the time of surgery, of whom four had stopped before the surgery. The smoking status of the three other patients was unknown. The surgical indication for breast reconstruction was isolated breast asymmetry in 11 patients, associated with Poland syndrome in one patient and an involuted thoracic congenital hemangioma with secondary breast aplasia in one patient (Figure 1). The mean harvested flap weight was $324 \mathrm{~g}$ (range $175 \mathrm{~g}$ to $519 \mathrm{~g}$ ). The mean length of hospital stay was six days (range three to 12 days). The vascular pedicle used was the inferior gluteal artery in all patients; no vascular anomaly was found at the donor site. The mean follow-up period was 24.0 months (range 1.5 to 66.5 months); two patients were lost in the first months of follow-up. Donor-site complications included three partial dehiscences, one of which was secondary to an infected seroma. Two patients received oral antibiotics and healed spontaneously.

Aesthetic evaluation of the donor site was performed using a physical assessment for six patients and photographic documentation for five more patients (Figure 2). Evaluation showed light scar hyperpigmentation in seven patients, which was associated with hypertrophic scarring. Lateral buttock flattening was noticeable in nine cases. There were three patients with some degree of inferior displacement of the inferior gluteal crease.
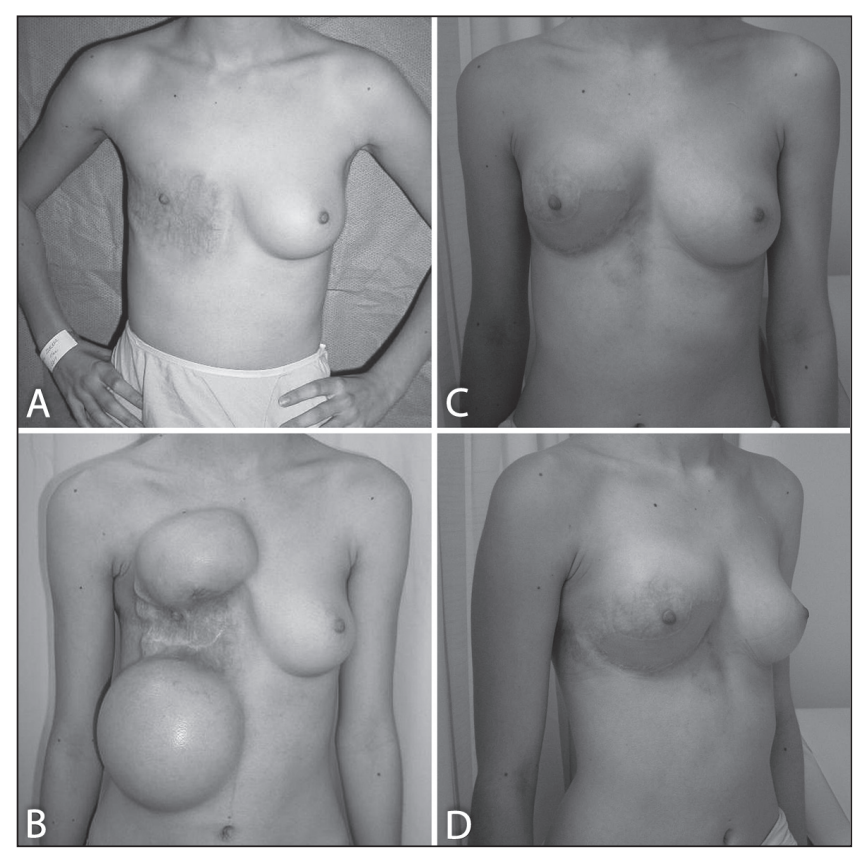

Figure 1) Patient with an involuted thoracic congenital hemangioma with secondary breast aplasia (A). Tissue expansion (B) was performed before reconstruction with an inferior gluteal artery perforator flap (C and D)

Of the six patients who presented for the appointment, central flattening of the buttock was perceptible in only one (from the superior view only). The mean scar length was $25.9 \mathrm{~cm}$ (range $20.5 \mathrm{~cm}$ to 31 $\mathrm{cm})$. Sensory testing showed no area of anesthesia of either the buttock or thigh. A zone of hypoesthesia over the scar was found in all six patients. A zone of decreased light touch (with finger) over the posterior thigh was found in all patients (Figure 3). This finding, however, was not corroborated with the Semmes-Weinstein monofilament test in four of six patients. This means that four patients were able to feel the same monofilament used on the normal side, indicating dysesthesia rather than hypoesthesia. This zone of dysesthesia measured a mean of $20.6 \mathrm{~cm} \times 9.2 \mathrm{~cm}$. One patient presented a zone of hypoesthesia on the buttock measuring $15 \mathrm{~cm} \times 4 \mathrm{~cm}$, in addition to her dysesthesia on the thigh, more than five years after the surgery.

Functional evaluation was performed in six patients and failed to reveal any postural anomaly or pelvic instability during the Trendelenburg testing. The Lasègue test was also negative in all patients. The gluteus maximus muscle strength in hip extension and hip abduction on the operated side was identical to the nonoperated side in all patients. The mean distance travelled for the 6 min walk test was $456.3 \mathrm{~m}$, which is within the normal range $(400 \mathrm{~m}$ to $700 \mathrm{~m}$ ) for a healthy subject with no limitations. Only one patient was below the inferior limit $(390 \mathrm{~m})$, but she did not report any perceived limitation.

A quality-of-life questionnaire was completed by eight patients. Six patients were satisfied $(n=3)$ or very satisfied $(n=3)$ with the surgery and would recommend it to a friend. One patient was indecisive, and one other believed that the procedure and pain involved were not warranted. Appearance of the operated buttock was rated 3.4 on a scale from 1 to 5 ( 5 being normal) compared with the normal side. None of the patients reported weakness during activities such as standing, walking, running, jumping or ascending stairs. Seven patients complained of a certain degree of paresthesia (defined as a sensation of numbness) over the posterior thigh and/or buttock, especially when sitting for long periods. Only one patient reported hypoesthesia over this area. Six patients described episodic light pain/discomfort (dysesthesia) over the buttock or scar on the operated side, mostly when sitting or at the end of the day. One patient described occasional itching that could not be relieved by scratching the area. 

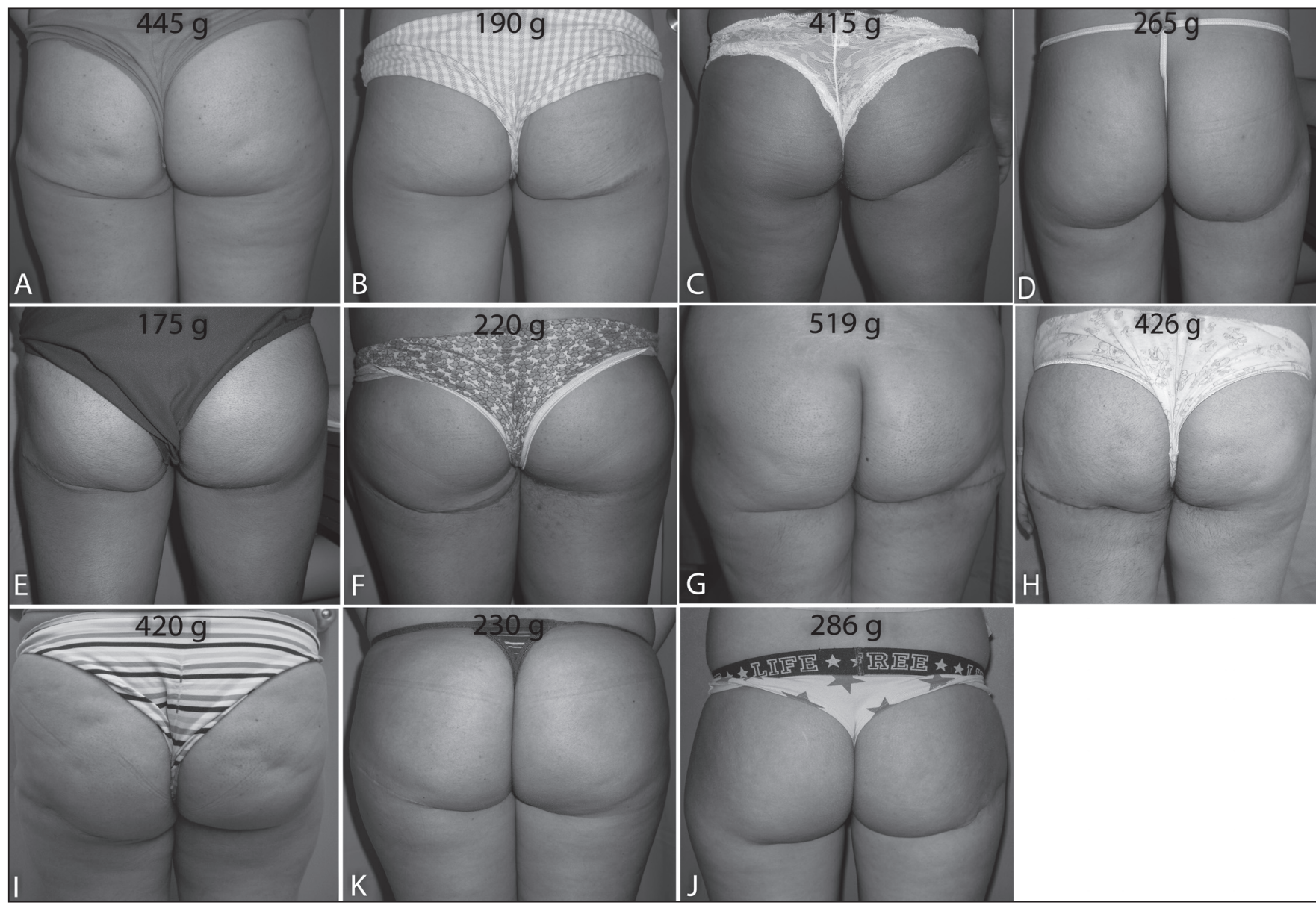

Figure 2) Donor site of 11 inferior gluteal artery perforator flaps with harvested flap weight noted. Note the minimal lateral buttock flattening in some patients and the inferior displacement of the inferior gluteal crease in patients $\mathbf{F}, \mathbf{H}$ and $\mathbf{I}$

\section{DISCUSSION}

Autologous breast reconstruction in teenage girls presents challenges related, in part, to the frequent limitation of sufficient adipose tissue in this population. The buttock area has become our preferred donor site for these patients given the consistent presence of sufficient tissues for adequate reconstruction.

Donor-site morbidity of the inferior gluteal musculocutaneous flap was studied by our team in 2007 (1). Similar to what was reported by Le-Quang (15), we did not find any motor function loss secondary to the gluteus maximus muscle partial harvest. However, a zone of hypoesthesia was objectively measured in all patients in the posterior thigh region.

With the advent of perforator flaps, donor-site morbidity was expected to be minimal. Regarding the IGAP flap, the gluteus maximus muscle is preserved, and the dissection of the vascular pedicle is performed through the muscle fibres until the inferior gluteal artery is reached. The inferior edge of the muscle is not elevated as is the case with the musculocutaneous flap; therefore, sensory impairment related to the dissection of the posterior femoral cutaneous nerve in that area should have been significantly reduced. Some reports on the IGAP flap have presented outcomes on the donor site, but none have quantitative or objective data. Dysesthesia on the posterior thigh and contour deformity were recurrent complaints of patients in these studies $(5,7,9,12,16)$.

In the present study, postoperative donor-site complications included three partial dehiscences, one of which was secondary to an infected seroma and treated with antibiotics and/or local wound care. As expected, we found no impairment of gluteus maximus muscle function nor pelvic instability. Sciatic nerve function was intact in all

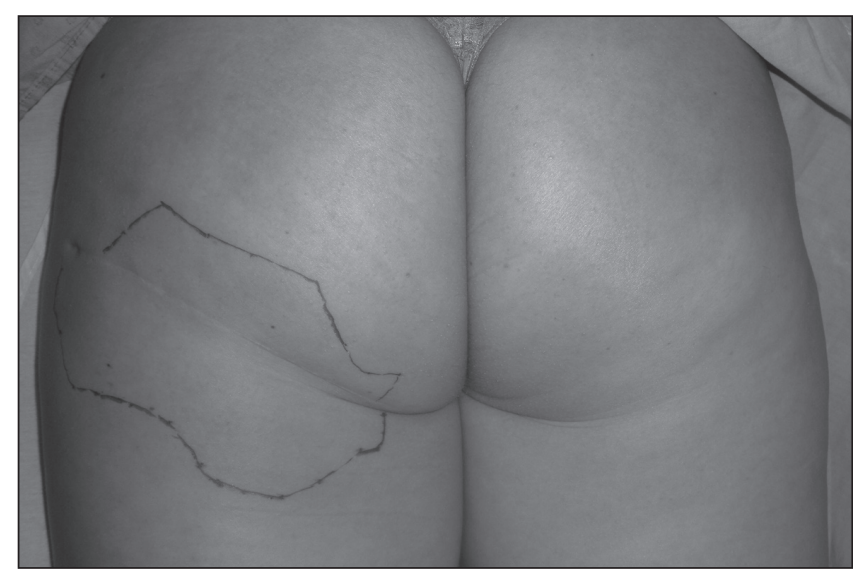

Figure 3) Zone of decreased light touch (marked), which was not corroborated with the monofilament test in four of six patients (zone of dysesthesia)

patients. In the questionnaire, seven of eight patients reported a zone of paresthesia (numbness), mostly inferior to the scar. Testing with the Semmes-Weinstein monofilament demonstrated hypoesthesia in that area for only two patients, therefore indicating dysesthesia for the other four patients. Two studies have documented the close anatomical relationship between the posterior femoral cutaneous nerve and the inferior gluteal pedicle at their exit point usually below the piriformis muscle $(17,18)$. They course together underneath the gluteus maximus muscle, where the nerve can cross or even loop around the 

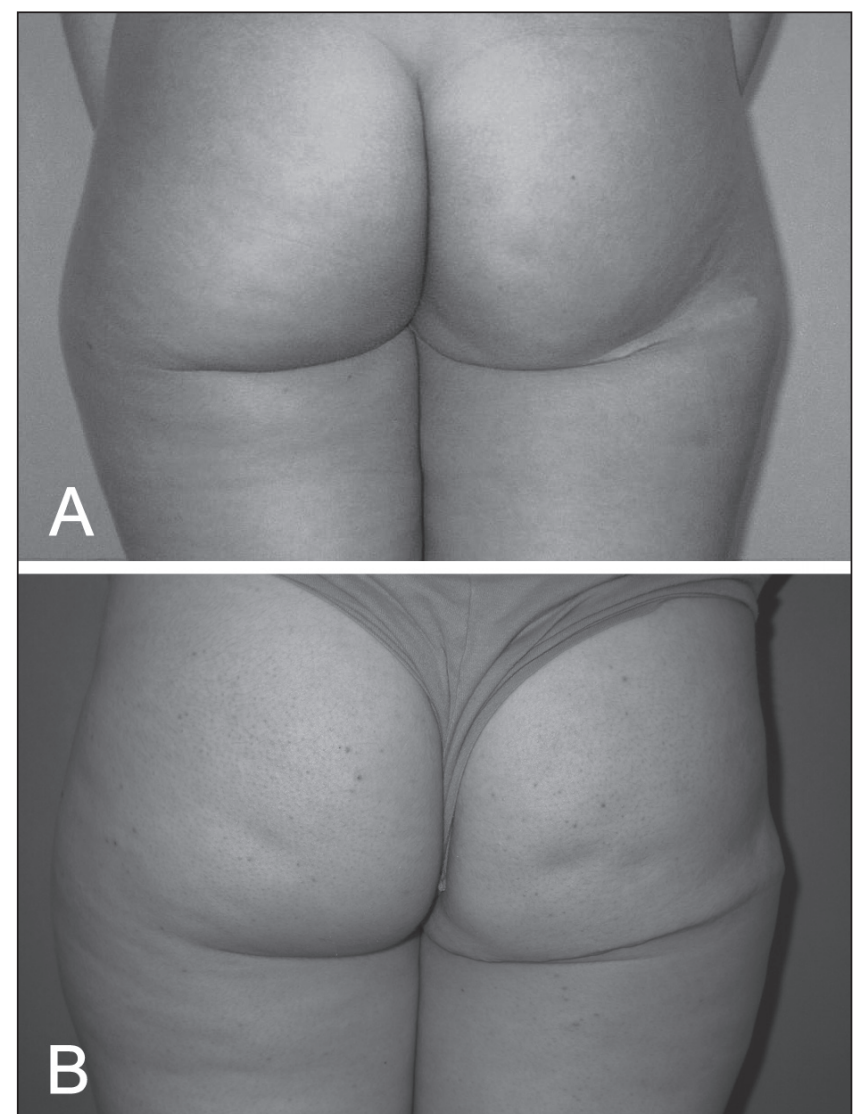

Figure 4) Comparison between lateral buttock depression caused by the partial gluteus maximus muscle harvest in an inferior gluteal musculocutaneous flap (A) and minimal lateral buttock flattening with the inferior gluteal artery perforator flap (B), with similar flap weight harvested $(510 \mathrm{~g}$ versus $445 \mathrm{~g}$ )

\section{REFERENCES}

1. Dupere S, Bergeron L, Bortoluzzi P, Del-Duca T, Caouette-Laberge L. Donor-site morbidity of the inferior gluteal musculocutaneous flap for breast reconstruction in teenagers. Ann Plast Surg 2007;59:617-20.

2. Allen RJ, Dupin CL, Dellacroce FJ. Perforator flaps in breast reconstruction. Perspectives in Plastic Surgery 2000;14:37-54.

3. Granzow JW, Levine JL, Chiu ES, Allen RJ. Breast reconstruction using perforator flaps. J Surg Oncol 2006;94:441-54.

4. Allen RJ, LoTempio MM, Granzow JW. Inferior gluteal perforator flaps for breast reconstruction. Semin Plast Surg 2006;20:89-94.

5. Levine JL, Miller Q, Vasile J, et al. Simultaneous bilateral breast reconstruction with in-the-crease inferior gluteal artery perforator flaps. Ann Plast Surg 2009;63:249-54.

6. Michlits W, Windhofer C, Papp C. Pectus excavatum and free fasciocutaneous infragluteal flap: A new technique for the correction of congenital asymptomatic chest wall deformities in adults. Plast Reconstr Surg 2009;124:1520-8.

7. Mirzabeigi MN, Au A, Jandali S, Natoli N, Sbitany H, Serletti JM. Trials and tribulations with the inferior gluteal artery perforator flap in autologous breast reconstruction. Plast Reconstr Surg 2011;128:614e-24e.

8. Kronowitz SJ. Redesigned gluteal artery perforator flap for breast reconstruction. Plast Reconstr Surg 2008;121:728-34.

9. LoTempio MM, Allen RJ. Breast reconstruction with SGAP and IGAP flaps. Plast Reconstr Surg 2010;126:393-401. inferior gluteal artery. Dysesthesia and hypoesthesia in the buttock and posterior thigh areas result from dissection and stretching of small branches of the posterior femoral cutaneous nerve. Some studies found that the dysesthesia disappeared with time $(5-7,9,10,16)$. This was not the case in our patients. The patient with the longest follow-up period (66.5 months) experienced persistent dysesthesia in an area measuring $19.5 \mathrm{~cm} \times 6 \mathrm{~cm}$. This dysesthesia was the major complaint in our questionnaire for six of eight patients. It may have been underestimated in previous reports because it was not a spontaneous complaint in our patients. Hypoesthesia over the scar was present in all patients.

Regarding the aesthetic aspect of the buttock, some degree of inferior displacement of the gluteal crease was found in three of 11 patients. In our previous study (1), no displacement was revealed. Nine patients experienced a lateral flattening of the buttock visible from the posterior view, which was less significant than the lateral depression caused when partially harvesting the gluteus maximus muscle in our previous study (Figure 4). Only one patient experienced minimal central flattening of the buttock from a superior view. Patients were moderately satisfied with the operated buttock in the questionnaire, their dissatisfaction being related to the scar rather than the deformity (the latter was reported by only two patients).

\section{CONCLUSION}

We believe that the inferior gluteal region remains a suitable donor site for teenage girls requiring breast reconstruction. Its acceptable morbidity rate and the large amount of available tissue make it one of the best options for thin young patients. Donor-site dysesthesia, paresthesia and hypoesthesia in the posterior thigh and inferior buttock regions remain a donor-site morbidity issue, regardless of the method of harvesting. Even with a careful dissection, the close relationship between the posterior femoral cutaneous nerve and the inferior gluteal artery explains the risk of stretching or sacrificing small branches of the nerve in the final proximal dissection of the pedicle. Using a perforator flap, therefore, incurs no benefit with regard to postoperative sensory issues, which were permanent in all of our patients. The IGAP flap does have the advantage of creating less lateral buttock depression compared with its musculocutaneous variant.

10. Allen RJ, Levine JL, Granzow JW. The in-the-crease inferior gluteal artery perforator flap for breast reconstruction. Plast Reconstr Surg 2006;118:333-9.

11. Heitmann C, Levine JL, Allen RJ. Gluteal artery perforator flaps. Clin Plast Surg 2007;34:123-30.

12. Granzow JW, Levine JL, Chiu ES, Allen RJ. Breast reconstruction with gluteal artery perforator flaps. J Plast Reconstr Aesthet Surg 2006;59:614-21.

13. O'Brien M. Aids to the investigation of peripheral nerve injuries. Brain 2010;133:2838-44.

14. Enright PL. The six-minute walk test. Respir Care 2003;48:783-5.

15. Le-Quang C. Microsurgical secondary breast reconstruction and free inferior gluteal flap [in French]. Annales de Chirurgie Plastique et Esthetique 1992;37:723-41.

16. Guerra AB, Metzinger SE, Bidros RS, Gill PS, Dupin CL, Allen RJ. Breast reconstruction with gluteal artery perforator (GAP) flaps: A critical analysis of 142 cases. Ann Plast Surg 2004;52:118-25.

17. Zenn MR, Millard JA. Free inferior gluteal flap harvest with sparing of the posterior femoral cutaneous nerve. J Reconstr Microsurg 2006;22:509-12.

18. Windhofer C, Brenner E, Moriggl B, Papp C. Relationship between the descending branch of the inferior gluteal artery and the posterior femoral cutaneous nerve applicable to flap surgery. Surg Radiol Anat 2002;24:253-7. 